\title{
Volume fractal dimension of soil particles and relationships with soil physical-chemical properties and plant species diversity in an alpine grassland under different disturbance degrees
}

\author{
YanYan LIU ${ }^{1}$, YanMing GONG ${ }^{1}$, Xin WANG ${ }^{2}$, YuKun $\mathrm{HU}^{1 *}$ \\ ${ }^{1}$ Key Laboratory of Biogeography and Bioresource in Arid Land, Xinjiang Institute of Ecology and Geography, Chinese Academy of \\ Sciences, Urumqi 830011, China; \\ ${ }^{2}$ Xinjiang Branch of Chinese Academy of Sciences, Urumqi 830011, China
}

\begin{abstract}
Fractal geometry is an important method in soil science, and many studies have used fractal theory to examine soil properties and the relationships with other eco-environmental factors. However, there have been few studies examining soil particle volume fractal dimension in alpine grasslands. To study the volume fractal dimension of soil particles $(D)$ and its relationships with soil salt, soil nutrient and plant species diversity, we conducted an experiment on an alpine grassland under different disturbance degrees: non-disturbance $\left(\mathrm{N}_{0}\right)$, light disturbance $(L)$, moderate disturbance $(\mathrm{M})$ and heavy disturbance $(\mathrm{H})$. The results showed that (1) Ds varied from 2.573 to 2.635 among the different disturbance degrees and increased with increasing degrees of disturbance. (2) Shannon-Wiener diversity index, Pielou's evenness index and Margalef richness index reached their highest values at the $M$ degree, indicating that moderate disturbance is beneficial to the increase of plant species diversity. (3) In the $L$ and $M$ degrees, there was a significant positive correlation between $D$ and clay content and a significant negative correlation between $D$ and soil organic matter (SOM). In the $\mathrm{H}$ degree, $D$ was significantly and positively correlated with total salt (TS). The results suggested that to a certain extent, $D$ can be used to characterize the uniformity of soil texture in addition to soil fertility characteristics. (4) For the $L$ degree, there was a significant negative correlation between $D$ and the Shannon-Wiener diversity index; while for the $M$ degree, there was a significant negative correlation between $D$ and Pielou's evenness index.
\end{abstract}

Keywords: alpine grassland; disturbance degree; volume fractal dimension of soil particles; species diversity

Citation: YanYan LIU, YanMing GONG, Xin WANG, YuKun HU. 2013. Volume fractal dimension of soil particles and relationships with soil physical-chemical properties and plant species diversity in an alpine grassland under different disturbance degrees. Journal of Arid Land, 5(4): 480-487. doi: $10.1007 / \mathrm{s} 40333-013-0184-9$

Mandelbrot is the first to propose fractal theory in the 1960s (Mandelbrot, 1967). This theory has been widely used in many natural and social science fields (Mandelbrot, 1977, 1982). Using fractal theory to quantitatively describe soil physical-chemical properties became an important method in soil science in the 1970s and the 1980s (Mandelbrot, 1977; Burrough, 1983; Armstrong, 1986; Scott and Stephen, 1989).
Based on the hypothesis that different soil particles are uniform in density, Tyler and Wheatcraft (1992) put forward the fractal dimension model. Thereafter, this model has been widely used to analyze soil particle size distribution (Huang and Zhan, 2002; Hu et al., 2005; Miao et al., 2007) and the fractal features of degraded soil structure (Gong and He, 2001). However, the assumption that different soil particles are

*Corresponding author: YuKun HU (E-mail: huyk@ms.xjb.ac.cn) Received 2012-12-14; revised 2013-02-05; accepted 2013-03-19

(C) Xinjiang Institute of Ecology and Geography, Chinese Academy of Sciences, Science Press and Springer-Verlag Berlin Heidelberg 2013 
uniform in density is not accepted by a number of scientists (Martin and Montero, 2002; Wang et al., 2005). Meanwhile, with the development and improvement of laser diffraction techniques, it is possible to accurately measure the size and mass of soil particles. So, Wang et al. (2005) modified and adjusted the Tyler and Wheatcraft's model and first put forward the concept and formula of volume fractal dimension of soil particles $(D)$. The concept and formula of $D$ was gradually accepted by researchers and applied in soil science. Many researches have shown that $D$ is a reasonable parameter to describe soil particle size distribution (Zeng et al., 2008; Shi et al., 2011). Furthermore, the relationships between $D$ and soil physical-chemical prosperities were also analyzed in recent year. Chen et al. (2010) showed that $D$ was significantly and positively correlated with total phosphorus content in Shenmu Colliery, North Shaanxi, China. Shi et al. (2011) found that $D$ s were significantly and positively correlated with soil $\mathrm{pH}$, clay and silt contents, and total phosphorus. However, few studies were conducted on alpine grasslands under different disturbance degrees. $D$ is an ideal soil fertility measurement index because $D$ can be used to characterize the influence of soil particle size on soil aggregation and reflect the homogeneity of soil texture in addition to soil permeability and erosion resistance. $D$ increased with increasingly compact soil structure and decreasing soil permeability, and vice versa (Jia et al., 2006; Shi et al., 2011).

Bayinbuluk grassland is one of the largest alpine grasslands in China, and it has a special significance for the ecological conservation in Xinjiang, especially South Xinjiang (Song, 2006). In the recent years, the grassland has degraded seriously due to some disturbance factors such as overgrazing, mowing, use of pesticides for the control of mice and insects, and the development of tourism (Song, 2006). As a result, researchers have paid an increasing attention to environmental problems in this grassland (Fan et al., 2008; Liu et al., 2008; Gong et al., 2010). There are quite many investigations to the alpine vegetation (Hu et al., 2007; Wang et al., 2009), but few studies address the $D$ use in this region. The objectives of this study are to: 1) analyze the $D$ in the alpine grassland under differ- ent disturbance degrees; and 2) explore the relationships of $D$ with the soil physical-chemical properties and plant species diversity in this grassland. Our study aimed to provide new scientific information that could be applied to alpine grassland restoration.

\section{Materials and methods}

\subsection{Study area}

The Bayinbuluk alpine grassland, with a mean altitude of 2,500 m, is located in the southern Tianshan Mountains of the Xinjiang Uygur autonomous region, China and covers a total area of approximately $23,000 \mathrm{~km}^{2}$. The mean annual precipitation in the area is $265.7 \mathrm{~mm}$, with $78.1 \%$ occurring from May to August. The annual mean temperature is $-4.8^{\circ} \mathrm{C}$, with the monthly mean lowest occurring in January $\left(-27.4^{\circ} \mathrm{C}\right)$ and the highest occurring in July $\left(11.2^{\circ} \mathrm{C}\right.$ ) (Li et al., 2012). The soil type is subalpine steppe soil (Erdawlat and Adeli, 1989). According to the results of past field studies in the Bayinbuluk alpine grassland (Gong et al., 2010), there are 36 plant species belonging to 26 genera and 16 families and the dominant species are Festuca ovina and Stipa purpurea.

\subsection{Methods}

\subsubsection{Experimental design and sampling methods}

The study was conducted at the Bayinbuluk Grassland Ecosystem Research Station of the Chinese Academy of Sciences in mid-August 2009. The soil parent material in the study area is loess, and the soil layer is $50-150 \mathrm{~cm}$ thick. Grazing is an important disturbance in the grassland. According to grazing intensity, we divided the disturbance into four types: non-disturbance ( $\mathrm{N}_{0}$, non-grazing), light disturbance (L, light grazing), moderate disturbance ( $\mathrm{M}$, moderate grazing), and heavy disturbance $(\mathrm{H}$, heavy grazing). We randomly selected five $10 \mathrm{~m} \times 10 \mathrm{~m}$ sampling sites in the area of each disturbance degree, with a total of 20 sampling sites. GPS was used to measure the longitude, latitude and altitude of each sampling site. The areal characteristics for different disturbance degrees are shown in Table 1.

At each sampling site, we randomly chose five 1 $\mathrm{m} \times 1 \mathrm{~m}$ quadrats, and recorded the vegetation type, species number, vegetation cover, plant height and 
Table 1 The areal characteristics for different disturbance degrees

\begin{tabular}{|c|c|c|c|c|c|c|c|c|}
\hline $\begin{array}{l}\text { Disturbance } \\
\text { degree }\end{array}$ & $\begin{array}{l}\text { Altitude } \\
(\mathrm{m})\end{array}$ & $\begin{array}{l}\text { Latitude } \\
(\mathrm{N})\end{array}$ & $\begin{array}{l}\text { Longitude } \\
\text { (E) }\end{array}$ & Dominant plant species & $\begin{array}{l}\mathrm{SOM} \\
(\mathrm{g} / \mathrm{kg})\end{array}$ & $\begin{array}{l}\mathrm{TN} \\
(\mathrm{g} / \mathrm{kg})\end{array}$ & $\begin{array}{l}\text { TS } \\
(\%)\end{array}$ & $\begin{array}{l}\mathrm{BD} \\
\left(\mathrm{g} / \mathrm{cm}^{3}\right)\end{array}$ \\
\hline $\mathrm{N}_{0}$ & 2,466 & $42^{\circ} 53^{\prime} 49^{\prime \prime}$ & $83^{\circ} 42^{\prime} 50^{\prime \prime}$ & Festuca ovina, Stipa purpurea, Carex atrofusca & 54.42 & 7.0 & 1.26 & 0.889 \\
\hline $\mathrm{L}$ & 2,470 & $42^{\circ} 53^{\prime} 08^{\prime \prime}$ & $83^{\circ} 42^{\prime} 20^{\prime \prime}$ & Festuca ovina, Potentilla anserina, Leymus tianschanicus & 50.37 & 5.6 & 1.32 & 0.947 \\
\hline M & 2,520 & $42^{\circ} 56^{\prime} 05^{\prime \prime}$ & $83^{\circ} 43^{\prime} 03^{\prime \prime}$ & Festuca ovina, Stipa purpurea, Koeleria cristata & 60.92 & 4.3 & 1.60 & 0.936 \\
\hline $\mathrm{H}$ & 2,465 & $42^{\circ} 53^{\prime} 30^{\prime \prime}$ & $83^{\circ} 42^{\prime} 30^{\prime \prime}$ & Leymus tianschanicus, Astragalus sp., Potentilla bifurca & 24.87 & 3.0 & 2.27 & 1.037 \\
\hline
\end{tabular}

Note: $\mathrm{N}_{0}$, non-disturbance; L, light disturbance; $\mathrm{M}$, moderate disturbance; $\mathrm{H}$, heavy disturbance. $\mathrm{SOM}=$ Soil organic matter; TN=Total nitrogen; TS=Total salt; $\mathrm{BD}=$ Bulk density.

relative frequency. In each quadrat, three soil samples were taken at $0-10,10-20,20-30 \mathrm{~cm}$ soil depths, respectively. Soil samples from the same soil depth of the five quadrats in each sampling site were mixed; therefore, 15 soil samples for the area of each disturbance degree were collected. Soil samples were analyzed in the laboratory.

\subsubsection{Plant species diversity}

We used the following formulas for calculating the Shannon-Wiener diversity index $(H)$, Margalef richness index $(E)$ and Pielou's evenness index $(J)$ of plant species diversity (Ma, 1994; Zhang, 2004):

$$
\begin{aligned}
& H=\sum P_{i} \ln P_{i}, \\
& E=(S-1) / \ln N, \\
& J=H / \ln S .
\end{aligned}
$$

Where $P_{i}$ is the relative importance value of species $i$ in each sampling site. The importance value of a species $=($ relative height + relative coverage + relative frequency)/3. $S$ is the total number of species $i$ in each sampling site, and $N$ is the total number of individuals in each sampling site.

\subsubsection{Soil analyses}

We used the potassium dichromate-sulfuric acid oxidation method to measure soil organic matter (SOM). For total nitrogen (TN), the potassium dichromate-sulfuric acid nitration method was used; for total salts (TS), we used the electronics conductivity method; and for bulk density (BD), we used the ring method. Soil particle size was analyzed using Malvern Laser Analyzer (Mastersizer 2000, UK). According to the American soil classification system, we divided the soil particle size into three types: clay $(<0.002 \mathrm{~mm})$, silt $(0.002-0.050 \mathrm{~mm})$ and sand $(0.050-2.000 \mathrm{~mm})$.

\subsubsection{Calculation of $D$}

$D$ was calculated using Eqs. $4 \mathrm{a}$ and $\mathrm{b}$ (Wang et al.,
2005):

$$
\begin{aligned}
& V\left(r>R_{i}\right) / V_{T}=1-\left(R_{i} / R_{\max }\right)^{(3-D)}, \\
& V\left(r<R_{i}\right) / V_{T}=1-\left(R_{i} / R_{\max }\right)^{(3-D)} .
\end{aligned}
$$

Where, $r$ is the soil particle diameter; $R_{i}$ is the characteristic scale; $R_{\max }$ is the maximum particle size; $V_{T}$ is the total soil particle volume; and $D$ is the volume fractal dimension of soil particles. $D$ can be estimated using linear regressions with logarithmically transformed data or non-linear regressions with non-transformed data.

\subsubsection{Data analysis}

All data analyses were performed using SPSS 13.0 for Windows (SPSS Inc., Chicago, IL, USA) and all figures were mapped using SigmaPlot 10.0.

\section{Results and discussion}

\subsection{Volume fractal dimension of soil particles $(D)$}

Our data analysis revealed that $D$ had a significant difference in the $0-10,10-20$ and $20-30 \mathrm{~cm}$ soil layers under the four disturbance degrees (Table 2). Overall, for the three soil layers of different disturbance degrees, $D$ s were all greater at the $\mathrm{H}$ degree $(2.620,2.631$ and 2.635 for $0-10,10-20$ and $20-30 \mathrm{~cm}$, respectively). In the $0-10$ and $10-20 \mathrm{~cm}$ soil layers, $D$ s were smaller for $\mathrm{L}$ and $\mathrm{M}$ degrees than that for the $\mathrm{N}_{0}$ degree, it is because the $\mathrm{N}_{0}$ degree is free of interference. As for the $\mathrm{L}$ and $M$ degrees, particles of smaller size (clay) in top soil sink because of animal trample, grassland degeneration and the shift of dominant plants from hemicryptophytes to rhizomatous geophytes. In addition, leaching, irrigation and other factors raised soil compactness, increased soil disturbance, and then caused the clay at the upper soil to move downward, so that $D$ was high at the lower soil layer and the $\mathrm{H}$ degree. 
Table 2 Soil particle size composition and volume fractal dimension of soil particles $(D)$ at different soil depths and for different disturbance degrees

\begin{tabular}{|c|c|c|c|c|c|c|}
\hline \multirow{2}{*}{$\begin{array}{l}\text { Soil depth } \\
\text { (cm) }\end{array}$} & \multirow{2}{*}{$\begin{array}{l}\text { Disturbance } \\
\text { degree }\end{array}$} & \multicolumn{3}{|c|}{ Soil particle size content $(\%)$} & \multirow{2}{*}{$D$} & \multirow{2}{*}{$\begin{array}{l}\text { Determination } \\
\text { coefficient }\left(R^{2}\right)\end{array}$} \\
\hline & & Sand & Silt & Clay & & \\
\hline \multirow{4}{*}{$0-10$} & $\mathrm{~N}_{0}$ & 23.146 & 70.966 & 5.888 & $2.597 \pm 0.106^{\mathrm{a}}$ & 0.814 \\
\hline & $\mathrm{L}$ & 31.498 & 62.871 & 5.630 & $2.573 \pm 0.173^{\mathrm{a}}$ & 0.846 \\
\hline & M & 19.469 & 74.313 & 6.218 & $2.589 \pm 0.089^{\mathrm{a}}$ & 0.813 \\
\hline & $\mathrm{H}$ & 18.567 & 74.112 & 7.320 & $2.620 \pm 0.064^{\mathrm{b}}$ & 0.796 \\
\hline \multirow{4}{*}{$10-20$} & $\mathrm{~N}_{0}$ & 17.411 & 75.295 & 7.293 & $2.621 \pm 0.231^{\mathrm{bc}}$ & 0.797 \\
\hline & $\mathrm{L}$ & 20.707 & 72.842 & 6.451 & $2.599 \pm 0.140^{\mathrm{a}}$ & 0.809 \\
\hline & M & 14.777 & 78.020 & 7.203 & $2.616 \pm 0.062^{\mathrm{c}}$ & 0.793 \\
\hline & $\mathrm{H}$ & 16.734 & 76.303 & 6.962 & $2.631 \pm 0.085^{b}$ & 0.797 \\
\hline \multirow{4}{*}{$20-30$} & $\mathrm{~N}_{0}$ & 21.080 & 73.078 & 5.843 & $2.583 \pm 0.065^{\mathrm{a}}$ & 0.809 \\
\hline & $\mathrm{L}$ & 18.842 & 73.762 & 7.396 & $2.624 \pm 0.136^{\mathrm{bc}}$ & 0.794 \\
\hline & M & 14.487 & 79.103 & 6.411 & $2.592 \pm 0.084^{\mathrm{a}}$ & 0.803 \\
\hline & $\mathrm{H}$ & 11.829 & 80.464 & 7.707 & $2.635 \pm 0.113^{\mathrm{c}}$ & 0.764 \\
\hline
\end{tabular}

Note: Means with different letters indicate significant differences at $P<0.05$; Mean \pm SD.

\subsection{Plant community composition and species di- versity}

The importance value is a quantitative index used to estimate the species position and function in a plant community (Li, 2004). The dominant species and its importance value changed with increasing degrees of grassland disturbance in the study area (Table 3). At the $\mathrm{N}_{0}$ degree, Festuca ovina and Stipa purpurea were the dominant species; but at the $\mathrm{H}$ degree, Astragalus sp. and Leymus tianschanicus became the dominant species. Generally, from the $\mathrm{N}_{0}$ to $\mathrm{H}$ degree, the importance value for Festuca ovina decreased from 21.77 to 0.00 , with a reduction of $100.00 \%$, and the value for Stipa purpurea decreased from 20.74 to 8.45, with a reduction of $59.26 \%$. However, the importance values of Leymus tianschanicus and Astragalus sp. all increased with the increase of disturbance degree. At the $\mathrm{N}_{0}$ degree, the importance value of Festuca ovina was higher, while that of Stipa purpurea was lower; however, at the $\mathrm{H}$ degree, the importance value of Stipa purpurea was far higher than that of Festuca ovina. The importance value of Festuca ovina first increased slightly at the L degree and then decreased rapidly until disappeared with increasing degrees of grassland disturbance, but the importance value of Stipa purpurea was higher at the M degree among the $\mathrm{L}, \mathrm{M}$ and $\mathrm{H}$ degrees, which means that the demands for nutrients by Stipa purpurea is greater than by Festuca ovina, and the salt tolerance of Festuca ovina is not as high as that of Stipa purpurea. The importance values of Leymus tianschanicus, Astragalus sp., and Taraxacum sp. increased by $139.05 \%, 243.09 \%$, and $212.59 \%$, respectively as disturbance increased from the $\mathrm{N}_{0}$ to the $\mathrm{H}$ degree. Leymus tianschanicus and Astragalus sp. became the dominant species at the $\mathrm{H}$ degree, with Stipa purpurea as a concomitant species. Therefore, the community's species composition appeared to change dramatically with increasing degrees of grassland disturbance.

With the increase of disturbance degree, the dominant species in the plant community were replaced by other species (Table 3 ). Under the $\mathrm{N}_{0}$ conditions, plant diversity was relatively low, and Festuca ovina and Stipa purpurea were the dominant species. At the L and $\mathrm{M}$ degrees, a large number of other species such as Astragalus sp. and Koeleria cristata invaded and expanded, and then occupied the dominant positions in the plant community. At the $\mathrm{H}$ degree, the community was mainly comprised by Leymus tianschanicus and Astragalus sp. With the increase of grassland disturbance, SOM content decreased, while soil TS and BD increased. However, at the M degree, SOM was higher because of the moderate amount of animal feces and plant litter, which made the species numbers 
Table 3 Cover and importance values of dominant plant species under different disturbance degrees

\begin{tabular}{|c|c|c|c|c|c|c|c|c|}
\hline \multirow{2}{*}{ Species name } & \multicolumn{4}{|c|}{ Cover $(\%)$} & \multicolumn{4}{|c|}{ Importance value } \\
\hline & $\mathrm{N}_{0}$ & $\mathrm{~L}$ & $\mathrm{M}$ & $\mathrm{H}$ & $\mathrm{N}_{0}$ & $\mathrm{~L}$ & $\mathrm{M}$ & $\mathrm{H}$ \\
\hline Festuca ovina & 37.02 & 39.76 & 19.88 & 0.00 & 21.77 & 23.67 & 14.46 & 0.00 \\
\hline Stipa purpurea & 31.32 & 1.53 & 12.23 & 0.28 & 20.74 & 5.93 & 13.53 & 8.45 \\
\hline Astragalus sp. & 2.14 & 3.82 & 14.53 & 53.07 & 7.52 & 6.94 & 10.43 & 25.80 \\
\hline Leymus tianschanicus & 6.65 & 16.31 & 0.00 & 41.98 & 10.96 & 13.72 & 0.00 & 26.20 \\
\hline Potentilla bifurca & 0.00 & 3.57 & 14.53 & 15.84 & 0.00 & 5.44 & 6.38 & 6.57 \\
\hline Potentilla multifida & 1.90 & 1.02 & 0.15 & 0.20 & 4.19 & 4.72 & 1.65 & 4.51 \\
\hline Koeleria cristata & 0.00 & 3.06 & 8.41 & 0.00 & 0.00 & 8.17 & 12.91 & 0.00 \\
\hline Agropyron cristatum & 0.95 & 7.14 & 3.82 & 0.00 & 3.98 & 8.08 & 8.26 & 0.00 \\
\hline Carex atrofusca & 6.65 & 2.55 & 15.29 & 0.20 & 8.32 & 4.43 & 11.84 & 3.33 \\
\hline Potentilla anserina & 2.61 & 16.31 & 3.44 & 0.87 & 4.49 & 11.71 & 4.92 & 5.29 \\
\hline Taraxacum sp. & 0.10 & 0.26 & 0.46 & 0.28 & 1.43 & 0.72 & 1.26 & 4.47 \\
\hline Schultzia crinita & 2.14 & 0.61 & 0.77 & 0.99 & 4.48 & 1.24 & 1.14 & 3.70 \\
\hline Leontopodium leontopodioides & 8.54 & 0.00 & 3.44 & 0.08 & 12.11 & 0.00 & 6.39 & 1.22 \\
\hline Heteropappus altaicus & 0.00 & 0.00 & 1.91 & 0.00 & 0.00 & 0.00 & 4.42 & 0.00 \\
\hline
\end{tabular}

increase. The dominant species Festuca ovina and Stipa purpurea gradually lost their dominant positions throughout the disturbance degrees because of their poor salt tolerance and the increase of grazing intensity, while other competitive plant species, such as Leymus tianschanicus, Astragalus sp., and Potentilla spp., gradually became the dominant species because of their low nutrient demands and high salt tolerance.

Species diversity is a quantitative measure representing numerous community features ( $\mathrm{Li}$ and Zhang, 2006). Many studies have shown that plant communities show high species diversity under the condition of moderate disturbance (Jiang et al., 2003; Wen et al., 2011). According to the results of plant species diversity under different disturbance degrees (Fig. 1), the Shannon-Wiener diversity index, Pielou's evenness index and Margalef richness index were significantly different $(P<0.01)$. The Shannon-Wiener diversity index and the Margalef richness index showed a unimodal change trend with the increase of disturbance. The results indicated that all the three kinds of plant species diversity indices reached their highest values at the $\mathrm{M}$ degree. It showed that under moderate disturbance, the plant species diversity was high because of moderate environmental heterogeneity. So, our results supported the intermediate-disturbance

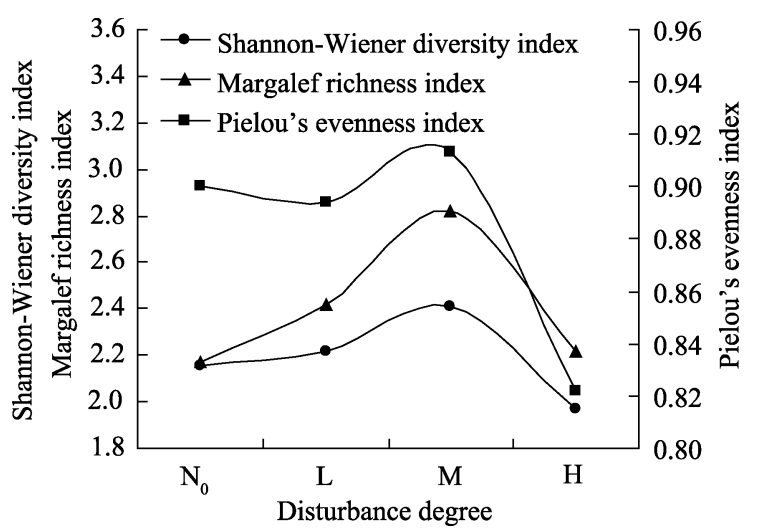

Fig. 1 Plant species diversity indices under different disturbance degrees

hypothesis (Connell, 1978; Milchunas et al., 1988).

\subsection{Relationship between $D$ and soil particle size}

Our analysis showed that the volume percentages of sand, silt, and clay in the study area were $11.83 \%{ }^{-}$ $31.50 \%, 62.87 \%-80.46 \%$, and $5.63 \%-7.71 \%$, respectively (Table 2). It showed that as the soil particle size increased, the air and water permeability was improved. According to the regression analysis, the determination coefficient $\left(R^{2}\right)$ of the $D$ for sand, silt, and clay was $0.499,0.409$, and 0.873 , respectively, being at a $99.95 \%$ significance level. The analysis demonstrated that there was a significant positive correlation between $D$ and clay content $\left(R^{2}=0.873, P<0.0001\right)$. 
The correlations between $D$ s and soil particle size contents varied among the different disturbance degrees (Table 4). For the $\mathrm{N}_{0}$ and $\mathrm{H}$ degrees, there was no significant correlation between $D$ s and soil particle size contents. However, for the $\mathrm{L}$ and $\mathrm{M}$ degrees, there was a significant positive correlation between $D$ and soil clay content. These results indicated that soil clay content had a significant effect on $D$, which was also affected by the maximum sizes of the soil particles. Shi et al. (2011) reported that $D$ was significantly and positively correlated with clay and silt contents, but significantly and negatively correlated with sand content. Our research demonstrated that there was a negative correlation between $D$ and sand content $(P=0.01)$, a positive correlation between $D$ and silt content $(P<0.05)$, and a significant and positive correlation between $D$ and clay content $(P<0.0001)$. The result showed that under a certain sand content, if the soil minimum size was larger, the $D$ was greater. Our result also indicated that $D$ can be used to characterize the uniformity of soil texture to a certain extent. With increasing degrees of grassland disturbance, soil sand content decreased while silt and clay contents increased, and $D$ increased as a result.

\subsection{Relationship between $D$ s and soil physical- chemical properties}

With the increase of disturbance degree, TS content and $\mathrm{BD}$ showed increasing trends, SOM and TN contents showed decreasing trends, but the highest value of SOM content being present at the M degree (Table 1). The correlations between $D \mathrm{~s}$ and soil physical-chemical properties differed among the different disturbance degrees (Table 5). There was a significant and negative correlation between $D$ and SOM at the $\mathrm{L}$

Table 4 Correlation analysis of volume fractal dimension of soil particles and soil particle size contents under different disturbance degrees

\begin{tabular}{llll}
\hline Disturbance degree & Sand & Silt & Clay \\
\hline $\mathrm{N}_{0}$ & -0.741 & 0.635 & 0.941 \\
$\mathrm{~L}$ & -0.930 & 0.906 & $0.999^{* *}$ \\
$\mathrm{M}$ & -0.542 & 0.397 & $0.996^{* *}$ \\
$\mathrm{H}$ & -0.868 & 0.905 & 0.279 \\
\hline
\end{tabular}

Note: ** means significance at the 0.01 level. and $\mathrm{M}$ degrees, a significant and negative correlation between $D$ and TN at the $\mathrm{L}$ and $\mathrm{H}$ degrees, and a significant and positive correlation between $D$ and TS at the $\mathrm{H}$ degree. Liu et al. (2011) showed that $D$ was significantly and negatively correlated with SOM and TN due to different vegetation types, but Ren et al. (2009) suggested that $D$ had a clear and positive correlation with SOM and TN $(P<0.01)$. Our result indicated that during the process of disturbance, soil salts move to the deeper soil layers at the $\mathrm{M}$ and $\mathrm{H}$ degrees through rain or irrigation eluviation. In contrast, in weakly disturbed or non-disturbed grasslands, soil salinity is higher near the ground surface because of the processes of transpiration and evaporation (Li et al., 2005). At the $\mathrm{M}$ degree, the plant species diversity was the highest, and as a result, plant biomass was higher than for the other degrees. At the same time, the speed of humus decomposition at the $\mathrm{M}$ degree was slower than at the other three degrees, which led to the highest value of SOM under this disturbance degree.

Soil BD is an important index of soil physical properties because $\mathrm{BD}$ values reflect soil permeability and ventilation (Qiu et al, 1998). Soil BD showed increasing trends with the increase of disturbance degree. The highest value of BD was present at the $\mathrm{H}$ degree, because the soil porosity, dispersion and aggregation structure were getting worse. Our result indicated that $D$ and soil particle composition showed a relatively significant relationship. This relationship didn't change with the variation of soil nutrient conditions, supporting the idea that $D$ can objectively reflect soil fertility levels.

Table 5 Correlation analysis of volume fractal dimension of soil particles and soil physical-chemical properties under different disturbance degrees

\begin{tabular}{lllll}
\hline Disturbance degree & SOM & TN & TS & BD \\
\hline $\mathrm{N}_{0}$ & 0.326 & 0.364 & 0.685 & -0.088 \\
$\mathrm{~L}$ & $-0.999^{* *}$ & $-0.980^{*}$ & -0.487 & 0.870 \\
$\mathrm{M}$ & $-0.991^{* *}$ & -0.288 & -0.291 & 0.266 \\
$\mathrm{H}$ & -0.894 & $-0.966^{*}$ & $0.961^{*}$ & 0.693 \\
\hline
\end{tabular}

Note: * and ${ }^{* *}$ mean significance at the 0.05 level and 0.01 level, respectively. 


\subsection{Relationship between $D$ and plant species di- versity}

The correlations between $D$ and plant species diversity differed among the different disturbance degrees (Table 6). From Table 6, we can know that for the $\mathrm{N}_{0}$ and $\mathrm{H}$ degrees, there were no significant correlations between $D$ s and plant species diversity indices; for the $\mathrm{L}$ degree, there was a significant and negative correlation between $D$ and the Shannon-Wiener diversity index; while for the $\mathrm{M}$ degree, $D$ was significantly and negatively correlated with Pielou's evenness index. Our study showed that soils with moderate $D$ values have better soil physical-chemical properties to improve the growth of plants and have higher plant species diversity indices. SOM content was higher at the $\mathrm{M}$ degree, making the soil suitable for plant root system development, plant germination, and plant growth. As a result, the plant species diversity indices reached their highest values at the $\mathrm{M}$ degree. Plant species diversity helps maintaining the ecosystem structure and stabilizing the ecosystem function. It is also index used to measure the ecosystem structure and function (Wen et al., 2011). Overall, $D$ values reflect not only soil conditions but also the stability of the plant community to some extent.

Table 6 Correlation analysis of volume fractal dimension of soil particles and plant species diversity under different disturbance degrees

\begin{tabular}{llll}
\hline $\begin{array}{l}\text { Disturbance } \\
\text { degree }\end{array}$ & $\begin{array}{l}\text { Shannon-Wiener } \\
\text { diversity index }\end{array}$ & $\begin{array}{l}\text { Pielou's evenness } \\
\text { index }\end{array}$ & $\begin{array}{l}\text { Margalef richness } \\
\text { index }\end{array}$ \\
\hline $\mathrm{N}_{0}$ & 0.230 & -0.785 & -0.710 \\
$\mathrm{~L}$ & $-0.962^{*}$ & 0.404 & -0.056 \\
$\mathrm{M}$ & -0.750 & $-0.963^{*}$ & 0.115 \\
$\mathrm{H}$ & -0.182 & 0.013 & -0.638 \\
\hline
\end{tabular}

Note: * means significance at the 0.05 level.

\section{Conclusions}

By summarizing our analyses on $D$ and the relationships with soil physical-chemical properties and plant species diversity under different disturbance degrees in the study area, we reached the following conclusions:

(1) Ds varied from 2.573 to 2.635 among different disturbance degrees and reached the highest values in the $\mathrm{H}$ degree. $D$ s increased with the increase of disturbance degree.

(2) All the three kinds of plant species diversity indices (Shannon-Wiener diversity index, Pielou's evenness index, and Margalef richness index) reached their highest values at the $\mathrm{M}$ degree. Our results supported the intermediate-disturbance hypothesis.

(3) $D$ was negatively correlated with sand content, and positively correlated with silt and clay contents. There was a significant and negative correlation between $D$ and SOM in the $\mathrm{L}$ and $\mathrm{M}$ degrees, a significant and negative correlation between $D$ and TN in the $\mathrm{L}$ and $\mathrm{H}$ degrees, and a significant and positive correlation between $D$ and TS in the $\mathrm{H}$ degree. The results suggested that to a certain extent, $D$ can be used to characterize the uniformity of soil texture in addition to soil fertility characteristics.

(4) $D$ was significantly negative correlated with the Shannon-Wiener diversity index in the $\mathrm{L}$ degree and negatively correlated with the Pielou's evenness index in the $\mathrm{M}$ degree. In the $\mathrm{M}$ degree, SOM content was higher, $D$ was moderate, and plant species diversity was also higher, indicating that $D$ can better describe the plant species diversity.

\section{Acknowledgments}

This study was financially supported by the National Basic Research Program of China (2009CB825103). The authors wish to express their deep gratitude to Professor David BLANK and Dr. WenXuan XU for their help in preparing the manuscript for publication.

\section{References}

Armstrong A C. 1986. On the fractal dimension of some transient soil properties. Journal of Soil Science, 37(4): 641-652.

Burrough P A. 1983. Multiscale sources of spatial variation in soil. I. The application of fractal concepts to nested levels of soil variation. Journal of Soil Science, 34(3): 577-597.

Chen X H, Duan Z H, Tan M L, et al. 2010. Changes in fractal dimension of soil particle during reversal of desertification-A case study in Yanchi County, Ningxia Hui Autonomous Region. Arid Zone Research, 27(2): 297-302.

Connell J H. 1978. Diversity in tropical rain forests and coral reefs. Science, 199: 1302-1310.

Erdawlat Merey, Adeli Maidi. 1989. Analysis on environmental condition and suitable utilization of grassland in Bayinbulak. Arid Zone Research, 6(Suppl.): 5-21. 
Fan Y G, Hu Y K, Li K H, et al. 2008. Effects of different disturbances on the diversity and biomass of the phytobiocoenoses in alpine steppes. Arid Zone Research, 25(4): 531-536.

Gong A D, He Y R. 2001. Study on fractal features of soil structure of degraded soil in dry and hot valley region of Jinsha River. Journal of Soi1 and Water Conservation, 15(3): 112-115.

Gong Y M, Hu Y K, Adeli Maidi, et al. 2010. Alpine grassland community characteristics at the different stages of degenerating succession in Bayanbulak. Journal of Arid Land Resources and Environment, 24(6): 149-152.

Hu Y F, Liu J Y, Zhuang D F, et al. 2005. Fractal dimension of soil particle size distribution under different and use/land coverage. Acta Pedologica Sinica, 42(2): 336-339.

Hu Y K, Li K H, Adeli Maidi, et al. 2007. Plant species diversity of alpine grasslands on southern slope of Tianshan Mountain along altitude gradient. Chinese Journal of Ecology, 26(2): 182-186.

Huang G H, Zhan W H. 2002. Fractal property of soil particle size distribution and its application. Acta Pedologica Sinica, 39(4): 490-497.

Jia X H, Li X R, Zhang J G, et al. 2006. Spatial heterogeneity analysis of fractal dimension of soil particle for Amopiptanhus mongolicus shrub. Acta Ecologica Sinica, 26(9): 2827-2833.

Jiang X L, Zhang W G, Yang Z Y, et al. 2003. The influence of disturbance on community structure and plant diversity of alpine meadow. Acta Botanica Boreali-Occidentalla Sinica, 23(9): 1479-1485.

Li B, Yang C, Lin P. 2004. Ecology. Beijing: Higher Education Press, 121.

Li J L, Zhang J T. 2006. Plant species diversity in the middle part of the Taihang Mountain. Chinese Journal of Applied and Environmental Biology, 12(6): 766-771.

Li K H, Gong Y M, Song W, et al. 2012. No significant nitrous oxide emissions during spring thaw under grazing and nitrogen addition in an alpine grassland. Global Change Biology, 18(8): 2546-2554.

Li Y, Wang Q J, Wang W Y, et al. 2005. Distribution and movement characteristics of soil water and soil salt during evaporation from perforated plastic mulch. Plant Nutrition and Fertilizer Science, 11(2): 187-193.

Liu A X, Gao Z L, Li Y H, et al. 2011. Fractal characteristics research on soil aggregates during highway slope vegetation restoration of different ages in Guanzhong Plain. Journal of Soil and Water Conservation, 25(1): 219-237.

Liu Y Y, Hu Y K, Yu J M, et al. 2008. Study on harmfulness of Pedicularis myriophylla and its control measures. Arid Zone Research, 25(6): 778-782.

Ma K P. 1994. Measurement of biotic community diversity: I. $\alpha$ diversity (Part 1). Biodiversity Science, 2(3): 162-168.

Mandelbrot B B. 1967. How long is the coast of Britain? Statistical self-similarity and fractional dimension. Science, 156: 636-638.
Mandelbrot B B. 1977. Fractals: Form, Chance and Dimension. San Francisco: Freeman, 352.

Mandelbrot B B. 1982. The Fractal Geometry of Nature. San Francisco: Freeman, 269.

Martin M A, Montero E. 2002. Laser diffraction and mutifractal analysis for the characterization of dry soil volume-size distributions. Soil and Tillage Research, 64: 113-123.

Miao C Y, Wang Y F, Wei X, et al. 2007. Fractal characteristics of soil particles in surface layer of black soil. Chinese Journal of Applied Ecology, 18(9): 1987-1993.

Milchunas D G, Sala O E, Lauenroth W K. 1988. A generalized model of the effects of grazing by large herbivores on grassland community structure. The American Naturalist, 132(1): 87-106.

Qiu R H, Yang Y S, Yu X T. 1998. Soil structure characteristics in the plantation of Cunninghamia lanceolata on different rotations. Journal of Beijing Forestry University, 20(4): 6-11.

Ren X, Chu G X, Wang G D, et al. 2009. Fractal dimension characteristics of soil particles in oasis desert Ecotone in southern edge of Junggar Basin. Journal of Desert Research, 29(2): 298-304.

Scott W T, Stephen W W. 1989. Application of fractal mathematics to soil water retention estimation. Soil Science Society of America Journal, 53: 987-996.

Shi Z F, Wang L, Wang J G. 2011. Volume fractal characteristics and significance of soil particles in the Shenmu colliery in north Shanxi province. Arid Zone Research, 28(3): 394-400.

Song Z S. 2006. It is urgent task to recover and comprehensively manage the grassland ecology of Bayingbuluke. Chinese Journal of Agricultural Resources and Regional Planning, 27(1): 21-25.

Tyler S W, Wheatcraft S W. 1992. Fractal scaling of soil particle-size distributions: analysis and linitations. Soil Science Society of America Journal, 56(2): 362-369.

Wang G L, Zhou S L, Zhao Q G. 2005. Volume fractal dimension of soil particles and its applications to land use. Acta Pedologica Sinica, 42(4): 545-550.

Wang X, Hu Y K, Rehemudula Adila, et al. 2009. Niche characteristics of Stipa purpurea community in alpine meadow of Bayanbulak. Arid Land Geography, 32(2): 255-260.

Wen L, Dong S K, Zhu L, et al. 2011. The effect of natural factors and disturbance intensity on spacial heterogeneity of plant diversity in alpine meadow. Acta Ecologica Sinica, 31(7): 1844-1854.

Zeng X Q, Liu H P, Lu B J, et al. 2008. Fractal dimension of soil particle-size distribution characteristic in the Beijing Mountains. Journal of Mountain Science, 26(1): 65-70.

Zhang J T. 2004. Quantitative Ecology. Beijing: Science Press, 77-96. 